\title{
SILAGEM DE CANA-DE-AÇÚCAR TRATADA COM INOCULANTES MICROBIANOS E SUAS MISTURAS
}

\author{
Rodrigo Lopes de Moraes ${ }^{1}$, Karina Guimarães Ribeiroํㅜㄹ Odilon Gomes Pereira ${ }^{1}$, Marcos Inácio \\ Marcondes ${ }^{1}$, Lucas Ladeira Cardoso ${ }^{* 1}$
}

\begin{abstract}
RESUMO - Objetivou-se avaliar a composição química, o perfil fermentativo, a população de micro-organismo e a recuperação de matéria seca de silagens de cana-de-açúcar tratada com diferentes misturas de inoculantes microbianos. Adotou-se o delineamento inteiramente casualizado, com seis tratamentos e três repetições. Os tratamentos consistiram de silagem de cana-de-açúcar (SC; Controle); SC + Lactobacillus buchneri (LB); SC + Propionibacterium acidipropionici (PA); SC + P. acidipropionici + Lactobacillus plantarum (PALP); SC + L. buchneri + P. acidipropionici (LBPA); SC + L. buchneri + P. acidipropionici + L. plantarum (LBPALP). A forragem foi picada e ensilada em baldes com capacidade de $20 \mathrm{~L}$, providos com válvulas de Bunsen, os quais foram abertos aos 90 dias após a vedação. Verificou-se que apenas o tratamento LB proporcionou teor de MS semelhante ao da silagem controle $(23,2 \%)$. Não houve efeito de inoculante sobre a produção de efluente, cuja média foi $104,31 \mathrm{~kg} / \mathrm{t}$ MN. Os tratamentos com PALP e LBPALP resultaram em menor recuperação de matéria seca que a silagem controle. Os teores de amônia e o $\mathrm{pH}$ foram incrementados pelos tratamentos com LBPA e LBPALP em relação à silagem controle. Não houve diferença entre os tratamentos para as populações de bactérias do ácido lático e leveduras, cujos valores médios foram 9,06 e 4,27 log ufc/g, respectivamente. Foi verificado maior teor de ácido lático na silagem LBPALP em relação a controle $(2,24 \%)$. A silagem com LBPA apresentou maior teor de etanol $(6,15 \%)$ em relação à silagem controle e PA. Assim, conclui-se que os inoculantes e suas misturas não proporcionam resultados promissores em relação à composição química, perfil de fermentação e recuperação de matéria seca da silagem de cana-de-açúcar.
\end{abstract}

Palavras-chave: ácidos orgânicos, composição química, etanol, nitrogênio amoniacal.

\section{SUGARCANE SILAGE TREATED WITH MICROBIAL INOCULANTS AND MIXTURES THEREOF}

\begin{abstract}
This study aimed to evaluate the chemical composition, fermentation profile, the population of microorganisms and the recovery of dry sugarcane silages. The experiment was conducted in a completely randomized design with six treatments and three replications. Treatments consisted of silage of sugarcane (SC) (Control); SC + Lactobacillus buchneri (LB); SC + Propionibacterium acidipropionici (PA); SC + P. acidipropionici + Lactobacillus plantarum (PALP); SC + L. buchneri + P. acidipropionici (LBPA); SC + L. buchneri $+P$. acidipropionici $+L$. plantarum $(L B P A L P)$. Forage was designed with buckets with a capacity of 20 liters, with Bunsen valves, which were opened 90 days after the sealing. It was verified that only the $L B$ treatment provided the DM content for the control of silage (23.2\%). There was no inoculation effect in an effluent production, whose average was $104.31 \mathrm{~kg} / \mathrm{t} M N$. The treatments with PALP and LBPALP resulted in lower dry matter recovery than a silage control. Ammonia contents and $p H$ were increased by treatments with LBPA and LBPALP in relation to control silage. There was no difference between the treatments for populations of lactic acid bacteria and yeasts, whose mean values were 9.06 and $4.27 \log c f u / g$, respectively. It was verified a higher lactic acid content in the LBPALP silage in relation to the control (2.24\%). The silage with $L B P A$ presented higher ethanol content (6.15\%) in relation to control silage and PA. Thus, it is concluded that the inoculants and their mixtures do not provide promising results regarding the chemical composition, fermentation profile and dry matter recovery of sugarcane silage.
\end{abstract}

Keywords: ammonia nitrogen, chemical composition, ethanol, organic acids.

${ }^{1}$ Departamento de Zootecnia, Universidade Federal de Viçosa, Viçosa, MG, Brasil. *Autor correspondente. Tel: +55 31 38993309; Fax: +55 31 3899-2275; E-mail: 1lccajuri@yahoo.com.br 


\section{INTRODUÇÃO}

A utilização da cana-de-açúcar como recurso forrageiro na alimentação de ruminantes é de fundamental importância, especialmente no período de escassez hídrica, que coincide com o momento de maturação e melhoria do seu valor nutritivo. A cana é uma forrageira com grande potencial de produção de massa seca e energia por área e permite bom desempenho dos animais, quando a dieta é corretamente suplementada com proteínas e minerais (Boin \& Tedeschi, 1993).

A ensilagem da cana-de-açúcar permite a concentração das operações de corte, picagem e armazenamento, facilita e maximiza a utilização da mãode-obra nas fazendas e melhora a logística para utilização. Entretanto, a ensilagem da cana-de-açúcar pode originar resultados indesejáveis, principalmente devido à ação de leveduras, que, no processo fermentativo da sacarose, pode desencadear perda acentuada de massa da matéria seca e no valor nutritivo, devido à conversão de açúcares em etanol, $\mathrm{CO}_{2}$ e água (Woolford, 1984).

Visando contornar resultados negativos e admitindo que a silagem de cana-de-açúcar necessite de aditivos que possibilitem controlar a principal forma de fermentação que ocorre, a alcoólica, e reduzir as perdas no valor nutritivo (Lima et al., 2007), assim, inoculantes microbianos (Siqueira et al., 2010; Miranda et al., 2011; Schmidt et al., 2011) têm sido utilizados com o intuito de obter silagem de boa qualidade e manter a qualidade fermentativa da silagem após abertura do silo. Normalmente, esse tipo de inoculante contém bactérias que foram selecionadas por capacidade de controlar a fermentação, promovendo o desenvolvimento dos micro-organismos benéficos e a inibição dos indesejáveis, como leveduras e clostrídios (Pedroso et al., 2007).

Utilizando doses de inoculante microbiano contendo Propionibacterium acidipropionici, Monção et al. (2012) avaliaram os seguintes tratamentos à base de silagem

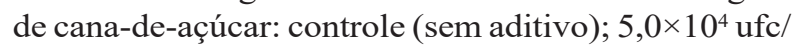
g; $1,0 \times 10^{5}$ ufc/g; $2,5 \times 10^{5}$ ufc/g; $5,0 \times 10^{5}$ ufc/g e $1,0 \times 10^{6}$ $\mathrm{ufc} / \mathrm{g}$ de massa ensilada. Os autores concluíram que o aditivo não atuou de forma eficiente no controle de perdas fermentativas, $\mathrm{pH}$ e população de leveduras.

Dentre os inoculantes microbianos, os efeitos do Lactobacillus buchneri na ensilagem de cana-de-açúcar têm sido mais estudados, verificando-se diminuição do $\mathrm{pH}$, da concentração de ácido lático e do número de leveduras, bem como, elevação da concentração de ácido acético e promoção de maior estabilidade aeróbica das silagens (Kleinschmit \& Kung, 2006; Mendes et al., 2008). Também tem sido verificada a ação do L. buchneri na redução das perdas de matéria seca e no controle da população de leveduras (Schmidt et al., 2008), o que pode ser fundamentada na elevação da concentração de ácido acético (Oude Elferink, 2001) que, segundo Moon (1983), é um composto capaz de inibir o crescimento de fungos.

São poucos os estudos com associação de inoculantes microbianos, havendo necessidade de mais avaliações para obtenção de resultados. Dessa forma, objetivou-se avaliar a composição química, o perfil fermentativo, as populações de micro-organismos e a recuperação de massa da matéria seca em silagens de cana-de-açúcar tratadas com diferentes inoculantes microbianos e suas misturas.

\section{MATERIAL E MÉTODOS}

O experimento foi realizado no Departamento de Zootecnia da Universidade Federal de Viçosa, localizada no município de Viçosa-MG, situada a $20^{\circ}$ e $45^{\prime}$ 'de latitude sul, $42^{\circ}$ e $51^{\prime}$ de longitude oeste.

Antes da ensilagem, o suco da cana-de-açúcar foi extraído manualmente por meio de esmagamento e torção do colmo, obtendo-se a concentração média de grau Brix por meio de um refratômetro de campo.

$\mathrm{O}$ experimento foi conduzido no delineamento inteiramente casualizado, com seis tratamentos e três repetições para cada tratamento, totalizando 18 unidades experimentais. Os tratamentos consistiram de silagem de cana-de-açúcar (SC; Controle); $\mathrm{SC}+$ Lactobacillus buchneri (LB); SC + Propionibacterium acidipropionici (PA); SC + P. acidipropionici + Lactobacillus plantarum (PALP); $\mathrm{SC}+$ L. buchneri + P. acidipropionici (LBPA); $\mathrm{SC}+L$. buchneri + P. acidipropionici + L. plantarum (LBPALP).

A composição química da cana-de-açúcar antes da ensilagem foi realizada para visualização das características dos efeitos da ensilagem e aplicação dos tratamentos sobre o material (Tabela 1).

MS: matéria seca; PB: proteína bruta; NIDA: nitrogênio insolúvel em detergente ácido em relação ao $\mathrm{N}$ total; FDN: fibra em detergente neutro; FDA: fibra em detergente ácido; BAL: população de bactérias ácido láticas; ENT: população de enterobactérias; LEV: população de leveduras. 
Tabela 1 - Composição química da cana-de-açúcar antes da ensilagem

\begin{tabular}{|c|c|c|c|c|c|c|c|c|c|}
\hline \multicolumn{10}{|c|}{ Planta cana-de-açúcar } \\
\hline $\begin{array}{l}\text { MS } \\
(\%)\end{array}$ & $\begin{array}{c}\mathrm{PB} \\
(\% \mathrm{MS})\end{array}$ & $\begin{array}{l}\text { NIDA } \\
(\%)\end{array}$ & $\begin{array}{l}\text { FDNcp } \\
(\% \mathrm{MS})\end{array}$ & $\begin{array}{c}\text { FDA } \\
(\% \mathrm{MS})\end{array}$ & $\begin{array}{l}\text { Brix } \\
\left({ }^{\circ}\right)\end{array}$ & $\begin{array}{c}\text { BAL } \\
(\log u f c / g)\end{array}$ & $\begin{array}{c}\text { ENT } \\
(\log u f c / g)\end{array}$ & $\begin{array}{c}\text { Mofos } \\
(\log u f c / g)\end{array}$ & $\begin{array}{c}\text { LEV } \\
(\log \mathrm{ufc} / \mathrm{g})\end{array}$ \\
\hline 24,70 & 3,70 & 9,60 & 51,60 & 32,00 & 20,00 & 7,72 & 5,97 & 4,53 & 5,61 \\
\hline
\end{tabular}

Os inoculantes microbianos foram adicionados à forragem por ocasião da ensilagem, de acordo com as recomendações da fabricante Lallemand Brasil LTDA, sendo o Lalsil Cana (L. buchneri $2,5 \times 10^{10} \mathrm{UFC} / \mathrm{g}$ ) aplicado na proporção de $2 \mathrm{~g}$ por tonelada de material picado, diluído em 2 L de água destilada; o Biomax Milho (L. plantarum e P. acidipropionici $2,5 \times 10^{10}$ $\mathrm{UFC} / \mathrm{g}$ ), aplicado na proporção de $2 \mathrm{~g}$ por tonelada de material picado, diluído em um $1 \mathrm{~L}$ de água destilada, e o Biomax Cana (P. acidipropionici 5,0 $\times 10^{9} \mathrm{UFC} /$ g) aplicado na proporção de 2,5 g por tonelada de material picado, diluído em 1 L de água destilada. A solução inoculante foi aspergida à forragem com auxílio de pulverizador costal com capacidade de $5 \mathrm{~L}$.

A cana-de-açúcar no momento da ensilagem apresentou tamanho médio de partículas de aproximadamente $1,0 \mathrm{~cm}$ e densidade de silagem de aproximadamente $700 \mathrm{~kg} / \mathrm{t} \mathrm{MN}$.

Os silos experimentais consistiram de baldes plásticos com capacidade para $20 \mathrm{~L}$, com tampas contendo válvulas de Bunsen para permitir o escape dos gases oriundos da fermentação. No fundo dos baldes, foram colocados $4 \mathrm{~kg}$ de areia seca, dentro de saco de tecido de algodão, evitando que a forragem entrasse em contato com a areia e permitindo a drenagem do efluente. A forragem foi compactada sobre o saco com areia, na quantidade média de $13,3 \mathrm{~kg}$ por silo. Os silos foram armazenados em área coberta, em local arejado, à temperatura ambiente, até o momento de abertura, a qual ocorreu aos 90 dias após a vedação. A porção superior (camada de $10 \mathrm{~cm}$ ) e inferior (camada de $10 \mathrm{~cm}$ ) da silagem foram descartadas e parte central da silagem foi homogeneizada para proceder a coleta de amostras.

As amostras foram acondicionadas em sacos de papel, identificadas, pesadas e pré secas em estufa com circulação forçada de ar à $55^{\circ} \mathrm{C}$, por 72 horas, procedendo-se, posteriormente, a moagem em moinho tipo Wiley, disposto de peneira de crivos $1 \mathrm{~mm}$. Foram determinados os teores de massa da matéria seca (MS, em \% da matéria natural) e, em \% da MS, proteína bruta (PB), fibra insolúvel em detergente neutro (FDNcp) e fibra insolúvel em detergente ácido (FDA); e nitrogênio insolúvel em detergente ácido em relação ao $\mathrm{N}$ total (NIDA/NT), segundo metodologia descrita por Detmann et al. (2012).

As perdas por efluente e a recuperação de massa da matéria seca foram calculadas conforme as equações descritas por Jobim et al. (2007).

Coletaram-se $50 \mathrm{~g}$ de silagem de cada silo, sendo que em $25 \mathrm{~g}$ foram adicionados $100 \mathrm{~mL}$ de água destilada, homogeneizados em liquidificador industrial por 1 minuto, e realizada a leitura do $\mathrm{pH}$ com uso de potenciômetro, nos demais $25 \mathrm{~g}$, foram adicionados 200 mL de solução de ácido sulfúrico 0,2 N, deixandose em repouso na geladeira por $48 \mathrm{~h}$ e, após este período, procedeu-se filtragem em papel de filtro para avaliação do teor de nitrogênio amoniacal $\left(\mathrm{NH}_{3}-\mathrm{N}\right)$ na solução filtrada, utilizando-se $\mathrm{KOH}$ a $2 \mathrm{~N}$, segundo Bolsen et al. (1992), sendo expresso como porcentagem do nitrogênio total $\left(\mathrm{NH}_{3}-\mathrm{N} / \mathrm{NT}\right)$.

A enumeração dos grupos bacterianos foi realizada a partir de $25 \mathrm{~g}$ de amostra, aos quais foram adicionadas $225 \mathrm{~mL}$ de solução tampão fosfato, obtendo-se a diluição de $10^{-1}$. Em seguida, diluições sucessivas foram realizadas, objetivando-se obter, na forragem antes da ensilagem, diluições variando de $10^{-3}$ a $10^{-7}$ para bactérias ácido láticas; de $10^{-2}$ a $10^{-6}$ para enterobactérias; de $10^{-1}$ e $10^{-5}$ para mofos e leveduras; e, nas silagens, diluições variando de $10^{-2}$ a $10^{-6}$ para bactérias ácido lácticas e de $10^{-1}$ e $10^{-5}$ para enterobactérias e mofos e leveduras. Foram consideradas passíveis de contagem as placas com valores entre 30 e 300 unidades formadoras de colônias (ufc). As populações microbianas foram quantificadas na forragem, antes da ensilagem e nas silagens, utilizando-se meios de cultura seletivos em placas de petri: MRS Ágar, para bactérias do ácido lático, Violet Red Bile, para enterobactérias e Petrifilm, para mofos e leveduras (Kung Junior, 1996). 
Para determinação dos ácidos orgânicos, aproximadamente $25 \mathrm{~g}$ de silagem foram diluídos em $225 \mathrm{~mL}$ de água destilada, homogeneizados em liquidificador industrial durante 1 minuto e os extratos aquosos obtidos foram filtrados, acidificados com solução de ácido metafosfórico $20 \%$ e centrifugados por 15 minutos, segundo metodologia descrita por Kung Junior (1996). Em seguida, as análises dos ácidos orgânicos e de etanol foram realizadas em Cromatógrafo Líquido de Alto Desempenho (HPLC).

A identificação e quantificação dos ácidos lático, acético, butírico e propiônico foram efetuadas segundo Siegfried et al. (1984), utilizando-se a coluna C18 (Fase Reversa), enquanto a identificação e quantificação de etanol foi efetuada utilizando-se a coluna HPX-87H), ambas da Biorad Laboratories.

Os dados foram submetidos à análise de variância e as médias comparadas pelo teste Tukey, ao nível de $5 \%$ de probabilidade, utilizando-se o procedimento PROC MIXED (SAS $\left.{ }^{\circledR}, 2016\right)$. Segundo McHugh (2011), o teste Tukey é o mais indicado para complementar os resultados da ANOVA, por ser o mais rigoroso (maior controle da taxa de erro tipo I) e poderoso (maior controle da taxa de erro tipo II).

\section{RESULTADOS E DISCUSSÃO}

Quanto à composição química das silagens, verificou-se efeito $(\mathrm{P}<0,05)$ de inoculante nos teores de MS, PB, NIDA/NT e recuperação de matéria seca (RMS). Para os teores de FDN, FDA e perda por efluente não foi constatada diferença $(\mathrm{P}>0,05)$ entre os tratamentos (Tabela 2).

Silagens com L. buchneri apresentaram teor de MS semelhante à silagem controle $(23,24 \%)$, que foi reduzido nos demais tratamentos $(\mathrm{P}<0,05)$ até $20,39 \%$ MS (LBPALP).

Observou-se menor teor de PB no tratamento PA em relação ao LBPA. Já o teor de NIDA foi maior no tratamento PA em relação ao LBPA e LBPALP. Tal comportamento pode ser explicado pelo teor de NIDA ser expresso em relação ao $\mathrm{N}$ total da amostra.

Os teores médios obtidos para FDN e FDA nas silagens foram 61,42 e $38,59 \%$, respectivamente, entretanto, verificaram-se aumentos nos teores de fibras em relação aos teores da cana-de-açúcar antes da ensilagem. É possível observação de que nenhum dos tratamentos ou associações foi capaz de promover melhorias significativas no teor de fibra desse material. Em estudo, Mendes et al. (2008) observaram teores de FDN e FDA aumentados, em comparação ao material original, mas semelhantes entre as silagens de canade-açúcar sem aditivo e com L. buchneri, indicando a conservação dos constituintes de parede celular nas silagens com uso deste inoculante microbiano.

A produção média de efluente (104,3 kg/t MN) é considerada elevada, se comparada aos valores citados na literatura para silagens de cana-de-açúcar inoculadas com aditivos microbianos, que variaram de 22,8 (Pedroso et al., 2007) a $84,9 \mathrm{~kg} / \mathrm{t}$ de matéria natural (Siqueira et al., 2007). Isto pode ser atribuído ao baixo teor de MS da cana-de-açúcar à ensilagem, ao pequeno tamanho de partícula (aproximadamente $1 \mathrm{~cm}$ ) e a densidade da silagem (700kg/t MN). Segundo Jobim et al. (2007), esses fatores podem afetar diretamente a produção de efluente na silagem.

Os tratamentos com PALB e LBPALP proporcionaram menor $(\mathrm{P}<0,05)$ recuperação de matéria seca (RMS), de 78,5 e 78,1\%, respectivamente, em relação à silagem controle $(82,1 \%)$, indicando dessa forma a menor efetividade desses tratamentos em promover diminuições de perdas totais de MS nas silagens de cana-de-açúcar. Os valores para RMS encontrados nesta pesquisa foram superiores ao valor médio de 71,6\%, obtido por Siqueira et al. (2007) em silagem de cana-de-açúcar sem e com uso de inoculantes microbianos.

Houve efeito de tratamentos para $\mathrm{pH}, \mathrm{NH}_{3}-\mathrm{N}$, população de mofos, concentrações de ácidos lático, acético e propiônico e etanol. Não houve efeito de tratamentos para as populações de bactérias ácido láticas e de leveduras, nem para o teor de ácido butírico (Tabela 3).

$\mathrm{O}$ teor de $\mathrm{pH}$ foi superior $(\mathrm{P}<0,05)$ nos tratamentos com LBPA e LBPALP, que proporcionaram valores de 3,31 e 3,32, respectivamente, em relação à silagem controle $(3,28)$. O teor de amônia do tratamento controle $(9,58$ $\mathrm{g} / \mathrm{kg} \mathrm{NT})$ foi menor $(\mathrm{P}<0,05)$ do que o visualizado nos demais tratamentos. Os valores de amônia se encontram no limite do nível crítico de $15 \%$, proposto por Mahanna (1993) para silagens de boa qualidade. Todos os valores de $\mathrm{pH}$ foram baixos, apresentando valores abaixo da faixa ideal, entre 3,8 e 4,2 (McDonald et al., 1991), indicando que houve decréscimo de $\mathrm{pH}$. 
Tabela 2 - Composição química, perda por efluente e recuperação de matéria seca dos tratamentos

\begin{tabular}{|c|c|c|c|c|c|c|c|c|}
\hline \multirow{2}{*}{ ' Item } & \multicolumn{8}{|c|}{ Tratamento } \\
\hline & Controle & LB & PA & PALP & LBPA & LBPALP & Sig. & EPM \\
\hline MS (\%) & $23,24^{\mathrm{a}}$ & $23,04^{\mathrm{ab}}$ & $21,62^{\mathrm{cd}}$ & $22,18^{\mathrm{bc}}$ & $20,65^{\mathrm{de}}$ & $20,39^{\mathrm{e}}$ & $*$ & 0,28 \\
\hline PB (\%MS) & $4,14^{\mathrm{ab}}$ & $4,23^{\mathrm{ab}}$ & $3,86^{\mathrm{b}}$ & $4,31^{\mathrm{ab}}$ & $4,47^{\mathrm{a}}$ & $4,39^{\mathrm{ab}}$ & $*$ & 0,76 \\
\hline FDNcp (\%MS) & 61,36 & 63,49 & 60,65 & 61,38 & 59,83 & 61,79 & $\mathrm{~ns}$ & 0,55 \\
\hline FDA (\%MS) & 38,54 & 39,48 & 38,46 & 38,30 & 37,99 & 38,78 & $\mathrm{~ns}$ & 0,33 \\
\hline NIDA/NT (\%MS) & $9,33^{\mathrm{ab}}$ & $11,19^{\mathrm{ab}}$ & $13,16^{\mathrm{a}}$ & $9,44^{\mathrm{ab}}$ & $8,48^{\mathrm{b}}$ & $8,43^{\mathrm{b}}$ & $*$ & 0,63 \\
\hline Efluente (kg/t MN) & 102,33 & 104,81 & 101,84 & 107,79 & 103,23 & 105,87 & $\mathrm{~ns}$ & 1,10 \\
\hline RMS (\%) & $82,13^{\mathrm{a}}$ & $81,82^{\mathrm{a}}$ & $79,40^{\mathrm{ab}}$ & $78,48^{\mathrm{b}}$ & $79,18^{\mathrm{ab}}$ & $78,08^{\mathrm{b}}$ & $*$ & 0,54 \\
\hline
\end{tabular}

Médias seguidas de mesma letra não diferem entre si pelo teste de Tukey (P>0,05). MS: matéria seca; PB: proteína bruta; FDNcp: fibra em detergente neutro corrigido para cinzas e proteina; FDA: fibra em detergente ácido; NIDA/NT: nitrogênio insolúvel em detergente ácido em relação ao N total; RMS: recuperação de matéria seca. Controle (SC): silagem de cana-de-açúcar sem inoculante; LB: SC + Lactobacillus buchneri; PA: SC + Propionibacterium acidipropionici; PALP: SC + P. acidipropionici + Lactobacillus plantarum; LBPA: SC + L. buchneri + P. acidipropionici; LBPALP: SC + L. buchneri + P. acidipropionici + L. plantarum. Sig.: Significância. EPM: erro padrão da média.

Tabela 3 - Perfil fermentativo, composição microbiana, produção de ácidos e etanol nas silagens

\begin{tabular}{|c|c|c|c|c|c|c|c|c|}
\hline \multirow{2}{*}{ Item } & \multicolumn{8}{|c|}{ Tratamento } \\
\hline & Controle & LB & PA & PALP & LBPA & LBPALP & Sig & EPM \\
\hline $\mathrm{pH}$ & $3,28^{\mathrm{c}}$ & $3,29^{\mathrm{bc}}$ & $3,29^{\mathrm{bc}}$ & $3,29^{\mathrm{bc}}$ & $3,31^{\mathrm{ab}}$ & $3,32^{\mathrm{a}}$ & $*$ & 0,003 \\
\hline $\mathrm{NH}_{3}-\mathrm{N}(\mathrm{g} / \mathrm{kg} \mathrm{NT})$ & $9,58^{\mathrm{b}}$ & $11,50^{\mathrm{ab}}$ & $13,95^{\mathrm{ab}}$ & $12,73^{\mathrm{ab}}$ & $14,56^{\mathrm{a}}$ & $15,03^{\mathrm{a}}$ & $*$ & 0,660 \\
\hline $\mathrm{BAL}(\log \mathrm{ufc} / \mathrm{g})$ & 9,06 & 9,08 & 9,05 & 9,05 & 9,03 & 9,08 & ns & 0,040 \\
\hline Leveduras $(\log$ ufc/g) & 4,28 & 4,08 & 4,44 & 4,33 & 3,81 & 4,67 & ns & 0,120 \\
\hline Mofos $(\log$ ufc/g) & $2,88^{\mathrm{a}}$ & $2,42^{\mathrm{bc}}$ & $2,30^{\mathrm{c}}$ & $2,36^{\mathrm{c}}$ & $2,73^{\mathrm{ab}}$ & $2,26^{\mathrm{c}}$ & $*$ & 0,070 \\
\hline Ác. lático (g/kg MS) & $22,40^{\mathrm{b}}$ & $21,30^{\mathrm{b}}$ & $26,10^{\mathrm{ab}}$ & $24,80^{\mathrm{ab}}$ & $26,30^{\mathrm{ab}}$ & $29,00^{\mathrm{a}}$ & $*$ & 0,086 \\
\hline Ác. acético (g/kg MS) & $18,50^{\mathrm{b}}$ & $16,70^{\mathrm{b}}$ & $22,60^{\mathrm{a}}$ & $23,00^{\mathrm{a}}$ & $24,10^{\mathrm{a}}$ & $24,10^{\mathrm{a}}$ & $*$ & 0,079 \\
\hline Ác. Propiônico (g/kg MS) & $0,60^{\mathrm{c}}$ & $0,80^{\mathrm{bc}}$ & $0,90^{\mathrm{ab}}$ & $0,80^{\mathrm{ab}}$ & $0,90^{\mathrm{a}}$ & $0,90^{\mathrm{a}}$ & $*$ & 0,002 \\
\hline Ác. butírico (g/kg MS) & 0,10 & 0,10 & 0,10 & 0,10 & 0,10 & 0,10 & ns & 0,001 \\
\hline Etanol (g/kg MS) & $4,03^{b}$ & $4,42^{\mathrm{ab}}$ & $4,22^{b}$ & $5,71^{\mathrm{ab}}$ & $6,15^{\mathrm{a}}$ & $4,99^{\mathrm{ab}}$ & $*$ & 0,280 \\
\hline
\end{tabular}

Médias seguidas de mesma letra não diferem entre si pelo teste de Tukey $(\mathrm{P}>0,05)$. Controle ( $\mathrm{SC})$ : silagem de cana-de-açúcar sem inoculante; LB: SC + Lactobacillus buchneri; PA: SC + Propionibacterium acidipropionici; PALP: SC + P. acidipropionici + Lactobacillus plantarum; LBPA: SC + L. buchneri + P. acidipropionici; LBPALP: SC + L. buchneri + P. acidipropionici + L. plantarum. Sig.: Significância. EPM: erro padrão da média.

A população de bactérias ácido láticas (BAL) nas silagens apresentou valor médio de $9,06 \mathrm{log} \mathrm{ufc} / \mathrm{g}$. Segundo Muck (1996), o valor mínimo recomendado de bactérias ácido láticas na forragem antes da ensilagem é de $5 \log$ ufc/g, para que haja adequada fermentação. Verifica-se que a população de BAL antes da ensilagem (7,72 log ufc/g) estava acima da mínima recomendada, o que possivelmente contribuiu para não se detectar diferença entre os tratamentos.

A população de leveduras apresentou valor médio de 4,27 log ufc/g. Assim, evidencia-se que nenhum dos inoculantes microbianos ou a associação destes foi capaz de contornar um dos principais problemas que ocorrem na silagem de cana-de-açúcar, que é a produção de leveduras. Pedroso et al. (2005) obtiveram contagem máxima de leveduras de 5,05 log ufc/g, no segundo dia após a ensilagem, e 4,5 log ufc/g, após quinze dias de fermentação da silagem de cana-deaçúcar, coincidindo com o ponto onde não se observou acréscimo de concentração de etanol na silagem, indicando que a atividade da levedura foi inibida pelo álcool e a massa ensilada foi estabilizada.

Menor população de mofos foi observada nas silagens inoculadas em relação à silagem controle $(2,88$ $\log$ ufc $/ \mathrm{g})$, porém não diferiu $(\mathrm{P}>0,05)$ da silagem tratada com LBPA. Portanto, com exceção deste, todos os inoculantes foram efetivos na redução de mofos.

Maior teor de ácido lático $(\mathrm{P}<0,05)$ foi observado na silagem LBPALP $(2,9 \%)$ em relação à controle e LB. Em silagens de cana-de-açúcar, Kung Junior \& Stanley 
(1982) observaram teor médio de 5,6\% na MS para a concentração de ácido lático. Pedroso et al. (2011) verificaram concentração média de ácido lático de $6,74 \%$ na MS para silagem de cana-de-açúcar.

A baixa presença de ácido lático visualizada pode ser em razão da metabolização por outros microorganismos de parte do ácido lático produzido na ensilagem. Essa evidência pode ser embasada em resultados obtidos por Bravo-Martins et al. (2006), que verificaram a presença de 81 cepas de leveduras em silagens de cana-de-açúcar,. Segundo os autores, a maioria das cepas assimilou lactato como substrato em culturas isoladas e, em aerobiose, o lactato tornouse o substrato preferencial no metabolismo da das espécies observadas.

Menor teor de ácido acético $(\mathrm{P}<0,05)$ foi verificado na silagem controle $(1,85 \%)$, que não diferiu da tratada com LB, sendo maiores os valores obtidos com os demais inoculantes. Segundo Mahanna (1994), são aceitáveis teores de ácido acético até $20 \mathrm{~g} / \mathrm{kg} \mathrm{MS}$, em silagens de boa qualidade. Portanto, os valores observados com uso de L. buchneri, P. acidipropionici, L. plantarum e suas associações foram um pouco superiores ao valor recomendado, o que indica ter ocorrido maior crescimento de enterobactérias, principais micro-organismos produtores de ácido acético e potente inibidor de leveduras (Moon, 1983).

As silagens proporcionaram maior teor de ácido propiônico $(\mathrm{P}<0,05)$ (com teores até $0,9 \mathrm{~g} / \mathrm{kg} \mathrm{MS}$ ), em relação à silagem controle $(0,6 \mathrm{~g} / \mathrm{kg} \mathrm{MS})$, exceto $\mathrm{LB}$, que manteve o teor deste ácido semelhante ao da silagem controle. Entretanto, segundo Mahanna (1994), são aceitáveis teores de ácido propiônico até $10 \mathrm{~g} / \mathrm{kg}$ MS nas silagens de boa qualidade, verificando-se valores nessa faixa em todas as silagens dessa pesquisa.

Verificou-se teor médio de ácido butírico $0,1 \mathrm{~g} /$ kg MS para as silagens. Este valor está abaixo do limite crítico registrado por Mahanna (1994) ( $1 \mathrm{~g} / \mathrm{kg} \mathrm{MS})$ para silagens de boa qualidade, o que indica que houve pouco crescimento de micro-organismos do gênero Clostridium, anaeróbio obrigatório e um dos principais responsáveis por perdas de matéria seca nas silagens.

Maior teor de etanol foi obtido na silagem com LBPA $(6,15 \%)$ em relação à silagem controle e PA, não diferindo das demais. A fermentação alcoólica resulta da presença de leveduras que utilizam açúcares e ácido lático, competidoras com as bactérias ácido láticas no início do processo fermentativo. De acordo com McDonald et al. (1991), a maior causa de perda de MS na silagem de cana-de-açúcar é a reação bioquímica da produção de etanol, em que a MS é catalisada via fermentação pelas leveduras, de modo que cada molécula de glicose fermentada gera duas moléculas de etanol, duas de dióxido de carbono e duas moléculas de água.

Os valores da concentração de etano encontrados nessa pesquisa foram inferiores a outros relatados na literatura para silagens de cana-de-açúcar, que estão na faixa de 6,9 a 19,3 g/kg MS (Freitas et al., 2006; Santos et al., 2010).

\section{CONCLUSÕES}

Os inoculantes microbianos e suas associações não proporcionam resultados promissores sobre a composição química, o perfil fermentativo, as populações microbianas e a recuperação de matéria seca da silagem de cana-de-açúcar.

\section{LITERATURA CITADA}

BOIN, C.; TEDESCHI, L.O. Cana-de-açúcar na alimentação de gado de corte. In: Simpósio sobre nutrição de bovinos, Piracicaba. Anais... Piracicaba: FEALQ, 1993. p.107-126.

BOLSEN, K.K.; LIN, C.; BRENT, B.E. et al. Effect of silage additives on the microbial succession and fermentation process of alfalfa and corn silages. Journal of Dairy Science, v. 75, p.3066-3083, 1992.

BRAVO-MARTINS, C.E.C.; CARNEIRO, H.; CASTRO-GOMÉZ, R.J.H. et al. Chemical and microbiological evaluation of ensiled sugar cane with different additives. Brazilian Journal of Microbiology, v.37, p.499-504, 2006.

DETMANN, E., SOUZA, M.A., VALADARES FILHO, S.C. et al. Métodos para análise de alimentos. Visconde do Rio Branco: Universidade Federal de Viçosa, 2012. 214p.

FREITAS, A.W.P.; PEREIRA, J.C.; ROCHA, F.C. et al. Características da silagem de cana-de-açúcar tratada com inoculante bacteriano e hidróxido de sódio e acrescida de resíduo da colheita de soja. Revista Brasileira de Zootecnia, v.35, p.48-59, 2006. 
JOBIM, C.C.; NUSSIO, L.G.; REIS, R.S. et al. Avanços metodológicos na avaliação da qualidade da forragem conservada. Revista Brasileira de Zootecnia, v.36, p.101-119, 2007.

KLEINSCHMIT, D.H.; KUNG JUNIOR., L. Metaanalysis of the effects of Lactobacillus buchneri on the fermentation and aerobic stability of corn and grass and small-grain silages. Journal of Dairy Science, v.89, p.40054013, 2006.

KUNG JR., L. Preparation of silage water extracts for chemical analyses. Standard operating procedure-001 2.03.96. Worrilow: University of Delaware, Ruminant Nutrition Laboratory, 1996. 309p.

KUNG JUNIOR, K.; STANLEY, R.W. Effect of stage of maturity on the nutritive value of wholeplant sugarcane preserved as silage.

Journal Animal Science, Albany, v.54, p.689-695, 1982.

LIMA, J.A.; CUNHA, E.A.; JUNIOR, E.F. et al. Valor nutritivo da silagem de cana-de-açúcar aditivada com hidróxido de cálcio. Boletim de Indústria Animal, v.64, p.329-338, 2007.

MAHANNA, B. Proper management assures highquality silage, grains. Feedstuffs, v.10, p.12-18, 1994.

MAHANNA, B. Troubleshooting silage problems. In: STATE APPLIED NUTRITION CONFERENCE, 4., 1993. Wisconsin. Proceedings... Wisconsin, 1993, p. 1-24.

McDONALD, P.; HENDERSON, A.R.; HERON, S.J.E. The biochemistry of silage. Ed. Marlow: Chalcombe Publications. 1991. 226p.

McHUGH, M.L. Multiple comparison analysis testing in ANOVA. Biochemia Medica, v. 21, p.203-209, 2011.

MENDES, Q.C.; SUSIN, I.; NUSSIO, L.G.et al. Efeito do Lactobacillus buchneri na fermentação, estabilidade aeróbia e no valor nutritivo de silagem de cana-de-açúcar. Revista

Brasileira de Zootecnia, v.37, p.2191-2198, 2008.
MIRANDA, D.C.L.; DIAS-JUNIOR, G.S.; LOPES, F. et al. Composição e pH de silagem de cana-deaçúcar com aditivos químicos e microbiológicos. Amazonian Journal, v.54, p.122-130, 2011.

MOON, N.J. Inhibition of the growth of acid tolerant yeasts by acetate, lactate and propionate and their synergistic mixtures. Journal of Applied Bacteriology, v.55, p.453-460, 1983.

MUCK, R. Silage inoculation. In: CONFERENCE WITH DAIRY AND INDUSTRIES, 1996, Madison. Proceedings... Dairy Forage Research Center, 1996, p.43-51.

OUDE ELFERINK, S.J.W.H.; KROONEMAN, J.; GOTTSCHAL, J.C. et al. Anaerobic conversion of lactic acid to acetic acid and 1,2-propanediol by Lactobacillus buchneri. Applied and

Environmental Microbiology, v.67, p.125$132,2001$.

PEDROSO, A.F.; RODRIGUES, A.A.; JUNIOR, W.B. et al. Fermentation parameters, quality and losses in sugarcane silages treated with chemical additives and a bacterial inoculant. Revista Brasileira de Zootecnia, v.40, p.2318-2322, 2011.

PEDROSO, A.F.; NUSSIO, L.G.; LOURES, D.R.S. et al. Efeito do tratamento com aditivos químicos e inoculantes bacterianos nas perdas e na qualidade de silagens de cana-de-açúcar. Revista Brasileira de Zootecnia, v.36, p.558-564, 2007.

PEDROSO, A.F.; NUSSIO, L.G.; PAZIANI, S.F. et al. Fermentation and epiphytic microflora dynamics in sugar cane silage. Scientia Agricola, v.62, p.427-432, 2005.

SANTOS, M.V.F., GÓMEZ CASTRO, A.G., PEREA, J.M. et al. Fatores que afetam o valor nutritivo das silagens de forrageiras tropicais. Archivos de Zootecnia, v.59, p.25-43, 2010.

SAS. Statistical Analysis System Institute. SAS/STAT. User's guide, version 9.4. Cary, North Carolina, v.2, 842 p. 2016.

SCHMIDT, P.; ROSSI-JUNIOR, P.; JUNGES, D. et al. Novos aditivos microbianos na ensilagem de cana-de-açúcar: composição bromatológica, perdas fermentativas, componentes voláteis estabilidade aeróbia. Revista Brasileira de Zootecnia, v.40, p.543-549, 2011. 
SCHMIDT, P. Aditivos químicos e biológicos no tratamento de cana-de-açúcar para alimentação de bovinos. In: JOBIM, C.C.; CECATO, U.; CANTO, M.W. (Eds) Produção e utilização de forragens conservadas. Maringá: Masson, 2008, p.117-152,

SIEGFRIED, V.R.; RUCKERMANN, H.; STUMPF, G. Method for the determination of organic acids in silage by high performance liquid chromatography. Landwirtsch. Forsch, v.37, p.298-304. 1984.
SIQUEIRA, G.R.; REIS, R.A.; SCHOCKEN-

ITURRINO, R.P. et al. Queima e aditivos químicos e bacterianos na ensilagem da cana-de-açúcar. Revista Brasileira de Zootecnia, v.39, p. 103-122, 2010.

SIQUEIRA, G.R.; REIS, R.A.; SCHOCKENITURRINO, R.P. et al. Perdas de silagens de canade-açúcar tratadas com aditivos químicos e bacterianos. Revista Brasileira de Zootecnia, v.36, p.2000-2009, 2007.

WOOLFORD, M.K. The silage fermentation. New York: Marcel Dekker inc., 1984. 350p.

Recebido para publicação em 21/1/2017 e aprovado em 7/6/2017 